\title{
Effect of Polyacrylamide Application on Water and Nutrient Movements in Soils
}

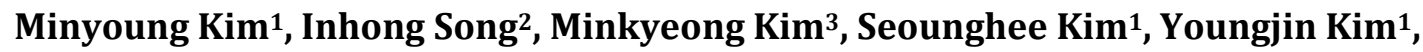 \\ Younghun Choi', Myungchul Seo ${ }^{4}$ \\ ${ }^{1}$ Department of Agricultural Engineering, National Academy of Agricultural Science, Rural Development \\ Administration, Jeonju, Korea \\ ${ }^{2}$ Research Institute for Agriculture and Life Sciences, Seoul National University, Seoul, Korea \\ ${ }^{3}$ Department of Agricultural Science, National Academy of Agricultural Science, Rural Development \\ Administration, Jeonju, Korea \\ ${ }^{4}$ Crop Production and Physiology Research Division, National Institute of Crop Science, Rural Development \\ Administration, Jeonju, Korea \\ Email: $\underline{\text { mykim75@korea.kr }}$
}

Received 19 August 2015; accepted 28 August 2015; published 31 August 2015

Copyright (C) 2015 by authors and Scientific Research Publishing Inc.

This work is licensed under the Creative Commons Attribution International License (CC BY).

http://creativecommons.org/licenses/by/4.0/

(c) (i) Open Access

\begin{abstract}
An understanding of nutrient movement in soil is important for developing management strategies to minimize nutrient leaching and surface movement, thus improving nutrient uptake by plants, maintaining a sustainable soil system, and even protecting groundwater quality. Polyacrylamide (PAM) is known as one of soil conditioner that functions to stabilize soil structure, increase infiltration, and reduce surface runoff. This study assesses the effects of PAM on the vertical movement of soil-water and major/minor nutrients $\mathrm{NO}_{3}-\mathrm{N}, \mathrm{NH}_{3}-\mathrm{N}, \mathrm{T}-\mathrm{N}, \mathrm{PO}_{4}-\mathrm{P}, \mathrm{T}-\mathrm{P}, \mathrm{K}, \mathrm{Ca}, \mathrm{Mg}$, and $\mathrm{Fe}$ ) in soils. Saturated hydraulic conductivity (Ksat) increases with increasing PAM concentrations up to $10 \mathrm{mg} \cdot \mathrm{L}^{-1}$ for sand and $20 \mathrm{mg} \cdot \mathrm{L}^{-1}$ for a mixture of sand and clay. Decreases in the loss of soluble nutrients, particularly $\mathrm{NH}_{3}-\mathrm{N}, \mathrm{PO}_{4}-\mathrm{P}$ and T-P, are observed as PAM concentrations increase. In contrast, PAM concentration has no effect on nitrate and minor nutrient levels. These results indicate that the application of PAM may be a viable method for protecting water bodies from excessive nutrients and improving nutrient availability for plants.
\end{abstract}

\section{Keywords}

Polyacrylamide, Water and Nutrient Movement, Breakthrough Curve, NaCl-Tracer, Soil Column, Major \& Minot Nutrients 


\section{Introduction}

The purpose of fertilization is to increase the nutrient content of crops, boost crop growth, and eventually produce better-quality agricultural products. The excessive use of fertilizers in agricultural settings has created numerous environmental problems, such as the degradation of soil quality, eutrophication, and the deterioration of the quality of surface water and groundwater [1].

An understanding of the relationship between soil water and plant nutrient movement is essential for efficient, economical fertilizer usage and the prevention of groundwater contamination. The amount of nutrient runoff from farm fields depends on the weather, the intensity and distribution of fertilizer use, the form of fertilizer and its application timing, land management practices, soil/aquifer characteristics, and the chemical properties of the nutrient compounds themselves [2]. Various nutrient management practices have been developed to maximize the value of fertilization and minimize its harmful side effects. They include: 1) applying nutrients at times and in amounts that minimize the amounts of fertilizer not taken up by crops; 2) maintaining good crop growing conditions (irrigation, nutrition and environmental protection) in order to minimize surface runoff losses and subsurface losses of plant nutrients; and 3) contouring, terracing, sod-based rotation, conservation tillage, no-tillage, and other practices using soil conditioners, e.g. polyacrylamide, gypsum, etc. [3].

Water-soluble polyacrylamide (PAM) is known as one of effective treatments for enhancing infiltration, reducing runoff and soil loss, and in some cases reducing nutrient losses from soils [4]-[6]. PAMs are inexpensive and can be applied to the soil surface quickly before irrigation [5]. In column experiments in which the surfaces of dry soils are treated with PAM, infiltration rates are reduced more in soil with a finer texture (silt loam) than in loamy sand soil [7]. In other column experiments using sandy loam soil, higher PAM concentrations result in lower infiltration rates, and solutions dominated by Na resulted in lower infiltration rates than solutions dominated by Ca (as gypsum) [8] [9].

In South Korea, previous studies have investigated to evaluate the applicability of PAM in soil erosion prevention and surface runoff reduction [10]-[12]. However, there have been no studies on the effects of PAM on factors other than soil erosion and runoff. In order to establish more optimal practices for PAM use, this study aims to quantify the effects of PAM application on the vertical movement of soil-water and major/minor nutrients.

\section{Materials and Methods}

\subsection{Experimental Procedure: Soil Column Experiment}

This study conducted two soil column experiments to evaluate the effects of PAM on the saturated hydraulic conductivity and nutrient leaching through soils. To cope with it, two different size of soil columns were used, one column of $9.7 \mathrm{~cm}$ in length and $3.1 \mathrm{~cm}$ in diameter for the saturated hydraulic conductivity experiment and the other column of $20.0 \mathrm{~cm}$ in length and $9.0 \mathrm{~cm}$ in diameter for the tracer and nutrient leaching experiment [13] (Figure 1(a) and Figure 1(b)). The soils used in these experiments consisted of Jumunjin standard sand (Jumunjin, South Korea) with a particle size of $0.718 \pm 0.123 \mathrm{~mm}$. The sand-clay mixture was a 9:1 mix of sand and clay containing 70\% - 90\% kaolin (Source Clay Minerals Repository, Columbia, MO, USA).

Samples were air-dried and slowly poured into a sterilized Plexiglas acrylic column in $1 \mathrm{~cm}$ increments. The columns were pre-filled with sterilized tap water, and stirred or tapped to prevent layering and air entrapment. The lower end of the columns were fitted with an end cap with a hole to allow the drainage water to pass through, and a filter paper was placed over the hole in each end cap. The filter paper facilitated uniform distribution of water over the entire surface of the column, so that the waterfront moved slowly through the soil column. An artificial rainfall simulator was designed to generate the precipitation event (Figure 1). PAM solution was prepared by slowly pouring $5 \mathrm{~g}$ of PAM (Magnafloc 336, BASF Korea, Korea) powder into $1 \mathrm{~L}$ of tap water and stirring overnight for complete mixing.

The first column study was conducted to evaluate the effect of texture type on saturated hydraulic conductivity. Water was applied from below to soil columns packed with sand and the sand-clay mixture until nearsaturated conditions were attained. PAM solution in concentrations of $0,10,20,30$ and $40 \mathrm{mg} \cdot \mathrm{L}^{-1}$ was sprayed on the sample surface. Infiltration samples were taken over time and the relationship between the measured infiltration rate and hydraulic head was used to calculate the saturated hydraulic conductivity, following the methods described by Oosterbaan and Nijland (1994) [14]. 

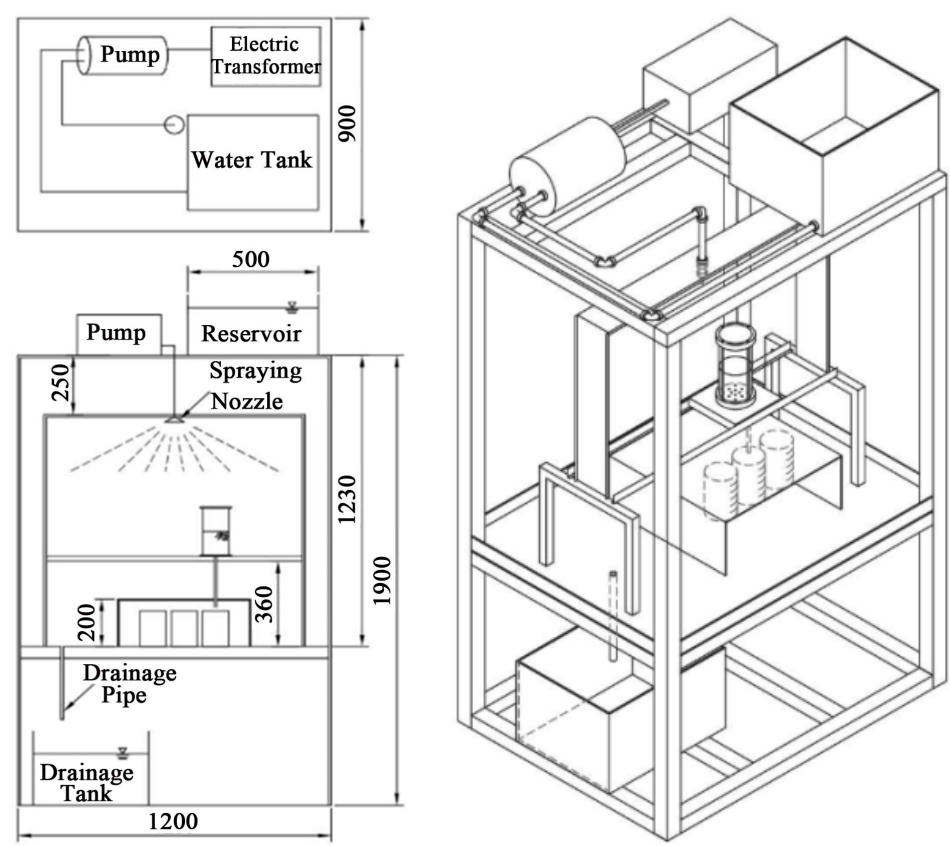

(1a)
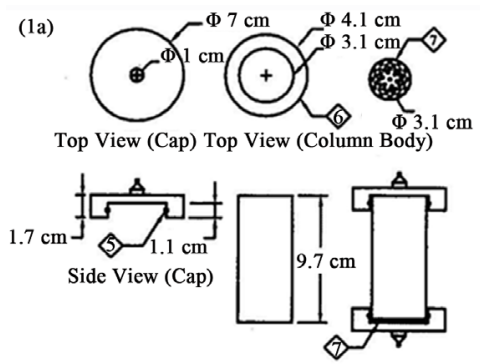

(modified from

Kim et al. (2009) [13])

(1b)

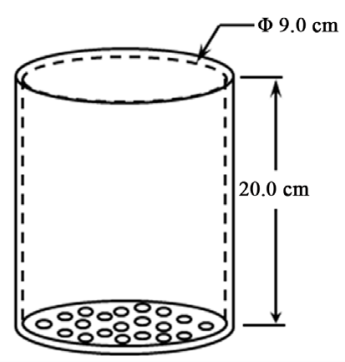

Figure 1. Schematic for the artificial rainfall simulator.

\subsection{Experimental Procedure: Nutrient Leaching Experiment}

A non-reactive tracer test using sodium chloride $(\mathrm{NaCl})$ was conducted by injecting a non-reactive tracer upstream and measuring its concentration downstream as a function of time. Predefined concentrations of $\mathrm{NaCl}$, PAM, and fertilizer were injected into columns packed with sand, and leachate samples were collected over time to investigate the passage of tracer and nutrients.

For the nutrient leaching experiment, saturated columns packed with sand were sprayed with tap water for 2 min, followed by PAM solution for 1 min and liquid fertilizer for $2 \mathrm{~min}$. Columns were then sprayed with tap water for $15 \mathrm{~min}$. PAM solutions consisted of a control $\left(0 \mathrm{mg} \cdot \mathrm{L}^{-1} \mathrm{PAM}\right)$ and two treatment concentrations (5 and $\left.10 \mathrm{mg} \cdot \mathrm{L}^{-1} \mathrm{PAM}\right)$. The injection rate for all solution was $178 \mathrm{~mL} \cdot \mathrm{min}^{-1}$. Leachate samples were collected every minute and kept at $4^{\circ} \mathrm{C}$ prior to chemical analysis. Experimental duration of 20 min was decided by monitoring the change of nutrient concentration (time with no further change). All experiments were repeated three times. The nutrient recovery rate was calculated as the total effluent amount of nutrients divided by the total influent amount of nutrients.

\subsection{Chemical Analysis}

Prior to nutrient leaching experiment, the tracer test with $200 \mathrm{mg} \cdot \mathrm{L}^{-1}$ of $\mathrm{NaCl}$ was injected and all effluent chloride concentrations were measured using ion chromatography (ICS-1500, Dionex Corp., Sunnyvale, CA, USA). After that, all nutrient leachates over time were used to quantify the concentrations of $\mathrm{NO}_{3}-\mathrm{N}, \mathrm{NH}_{3}-\mathrm{N}, \mathrm{T}-\mathrm{N}, \mathrm{T}-\mathrm{P}$, $\mathrm{PO}_{4}-\mathrm{P}, \mathrm{K}, \mathrm{Ca}, \mathrm{Mg}$, and $\mathrm{Fe}$. $\mathrm{NO}_{3}-\mathrm{N}$ and $\mathrm{PO}_{4}-\mathrm{P}$ were quantified using a Metrohm 881 Compact Ion Chromatograph (IC) pro with 858 samplers (Metrohm, Herisau, Switzerland). For $\mathrm{NH}_{3}-\mathrm{N}$ quantification, the residual dye concentration was analyzed by a GBC Cintra 202 UV-Vis spectrophotometer (GBC Scientific, Hampshire, USA) at $630 \mathrm{~nm}$ after each adsorption operation. Total $\mathrm{N}$ and $\mathrm{P}$ were independently analyzed using alkaline persulfate digestion followed by colorimetric detection using continuous flow analysis (BLTEC Korea Limited, Korea). The concentrations of $\mathrm{K}, \mathrm{Na}, \mathrm{Ca}, \mathrm{Mg}, \mathrm{Fe}, \mathrm{Mn}$, and B were determined through inductively coupled plasma optical-emission spectrometry (ICP-OES) using a PerkinElmer Optima 8300 spectroscope (PerkinElmer, Massachusetts, USA). All analyses followed standard methods [15].

\section{Results and Discussion}

The addition of PAM increased hydraulic conductivity, although this effect reached a plateau at $10 \mathrm{mg} \cdot \mathrm{L}^{-1} \mathrm{PAM}$ 
for the sand-clay soil and $20 \mathrm{mg} \cdot \mathrm{L}^{-1}$ for sand alone, and did not continue to increase at higher PAM concentrations (Figure 2). Sand alone exhibited a higher conductivity than the sand-clay mixture (Figure 2) in all cases with various PAM concentrations $\left(0,10,20,30\right.$ and $\left.40 \mathrm{mg} \cdot \mathrm{L}^{-1}\right)$. These results are consistent with previous work Silva et al. (2013) [16] showing that a sandy horizon has a higher hydraulic conductivity in the absence of PAM; that the agglutinating action of PAM provides higher water retention, reducing water drainage and also Ksat values; and that high concentrations of PAM $(0.01 \%$ PAM) do not increase conductivity over the values seen at medium concentrations of PAM, due to the viscosity of the PAM solution and the plugging of larger soil pores near the soil surface.

The mass recovery rate of $\mathrm{NaCl}$ was close to $100 \%$ because it is a non-reactive tracer; however, the mass recovery rate for $\mathrm{NO}_{3}-\mathrm{N}$ did not reach $100 \%$ due to the interaction of $\mathrm{NO}_{3}-\mathrm{N}$ with soil. Even though the tailing limb was observed with higher PAM application, the total injected mass was not fully recovered, indicating that nutrient components are irreversibly absorbed within soil pore spaces. Other nutrients $\left(\mathrm{NH}_{3}-\mathrm{N}, \mathrm{T}-\mathrm{N}, \mathrm{T}-\mathrm{P}\right.$, and $\mathrm{PO}_{4}-\mathrm{P}$ ) also showed less than $100 \%$ mass recovery rates.

In Figure 3, the breakthrough curves of nitrate as nitrogen $\left(\mathrm{NO}_{3}-\mathrm{N}\right)$ with and without PAM treatment were compared with the breakthrough curve of $\mathrm{NaCl}$ for flow pattern analysis. Without PAM, the rising limb, plateau portion and no tailing limb of the breakthrough curve suggest quicker solute transport paths. As PAM increases, it leads to a low peak concentration and a late tail of the breakthrough curve. This indicates that PAM application affects solute transport and retention in soil.

The $\mathrm{SiAlO}_{4}^{-}$in clay has a negative charge, but sand $\left(\mathrm{Si}_{2} \mathrm{O}_{4}\right)$ particles have no charge and do not retain cations [17]. However, the addition of PAM to soil changes the charge of the soil surface, which becomes somewhat negative [18]. This explains the high solubility and mobility of $\mathrm{NO}_{3}-\mathrm{N}$ with increasing application of PAM. A similar pattern is seen for T-N (Figure 4) because $\mathrm{NO}_{3-}$ is the primary form of nitrogen. As PAM concentrations increased 0 up to $10 \mathrm{mg} \cdot \mathrm{L}^{-1}$, the recovery rates were increased $9.2 \%$ for $\mathrm{NO}_{3}-\mathrm{N}$ and $11.5 \%$ for T-N, respectively. In contrary, the recovery rates for $\mathrm{NH}_{3}-\mathrm{N}, \mathrm{PO}_{4}-\mathrm{P}$ and T-P were decreased to $18.0 \%, 48.3 \%$, and $9.5 \%$, respectively. In the case of minor nutrients, there were no statistically significant increase or decrease as PAM was applied $(p>0.05)$.

\section{Conclusions}

This study found that an increase in PAM concentration increased Ksat to some degree, depending upon the soil type. However, at higher PAM concentration $\left(10 \mathrm{mg} \cdot \mathrm{L}^{-1} \mathrm{PAM}\right.$ for the sand-clay soil and $20 \mathrm{mg} \cdot \mathrm{L}^{-1}$ for sand alone), the saturated conductivity was decreased and this could be explained by viscous effect of PAM which might clog larger soil pores or form a distinct layer on the soil surface.

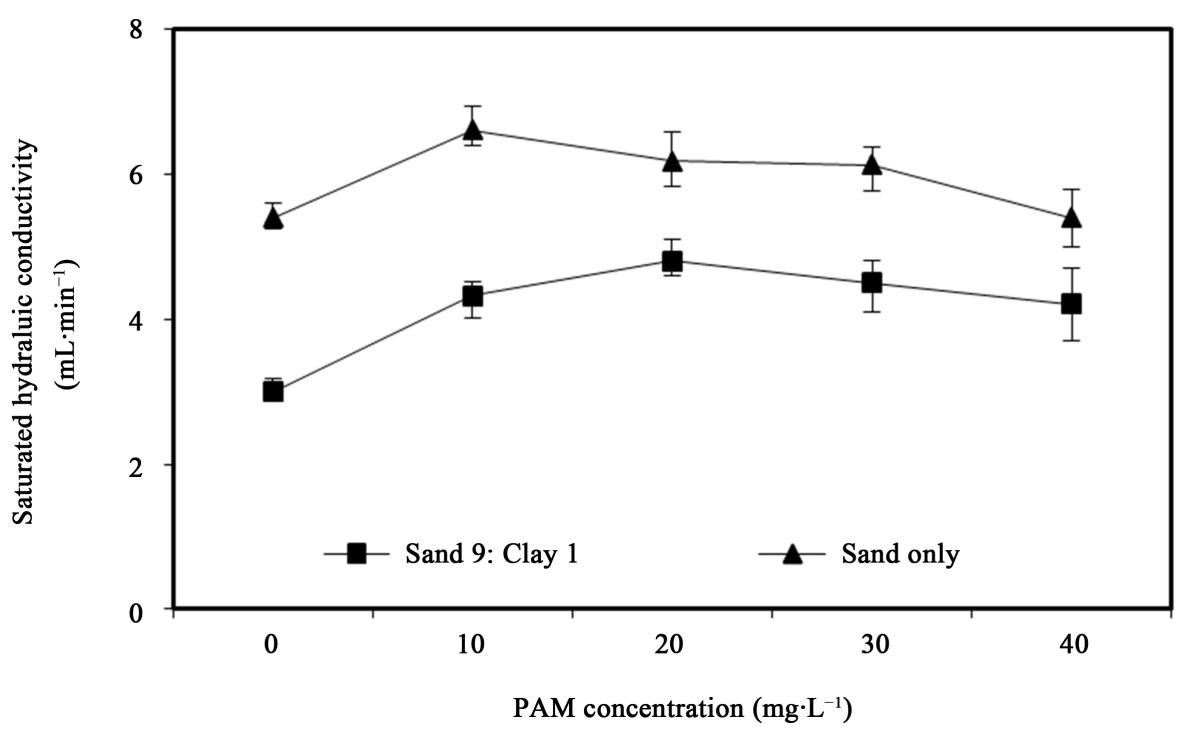

Figure 2. Saturated hydraulic conductivity at different PAM concentrations in sandy-clay soil and sand alone. 


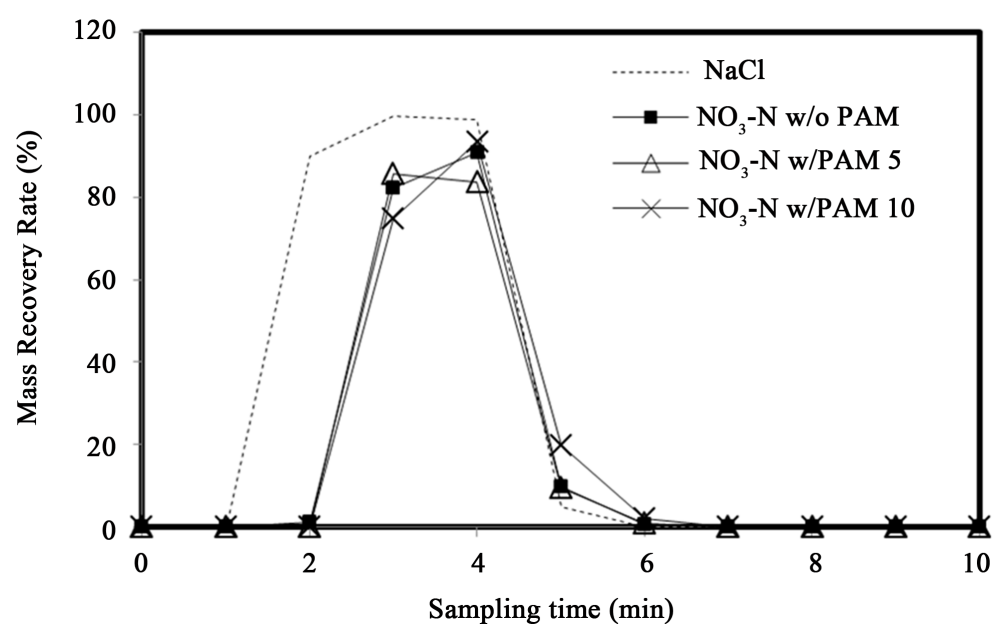

Figure 3. Breakthrough curves for $\mathrm{NaCl}$ at $0 \mathrm{mg} \cdot \mathrm{L}^{-1} \mathrm{PAM}$ and nitrate as nitrogen $\left(\mathrm{NO}_{3}-\mathrm{N}\right)$ at different concentraitons of PAM.

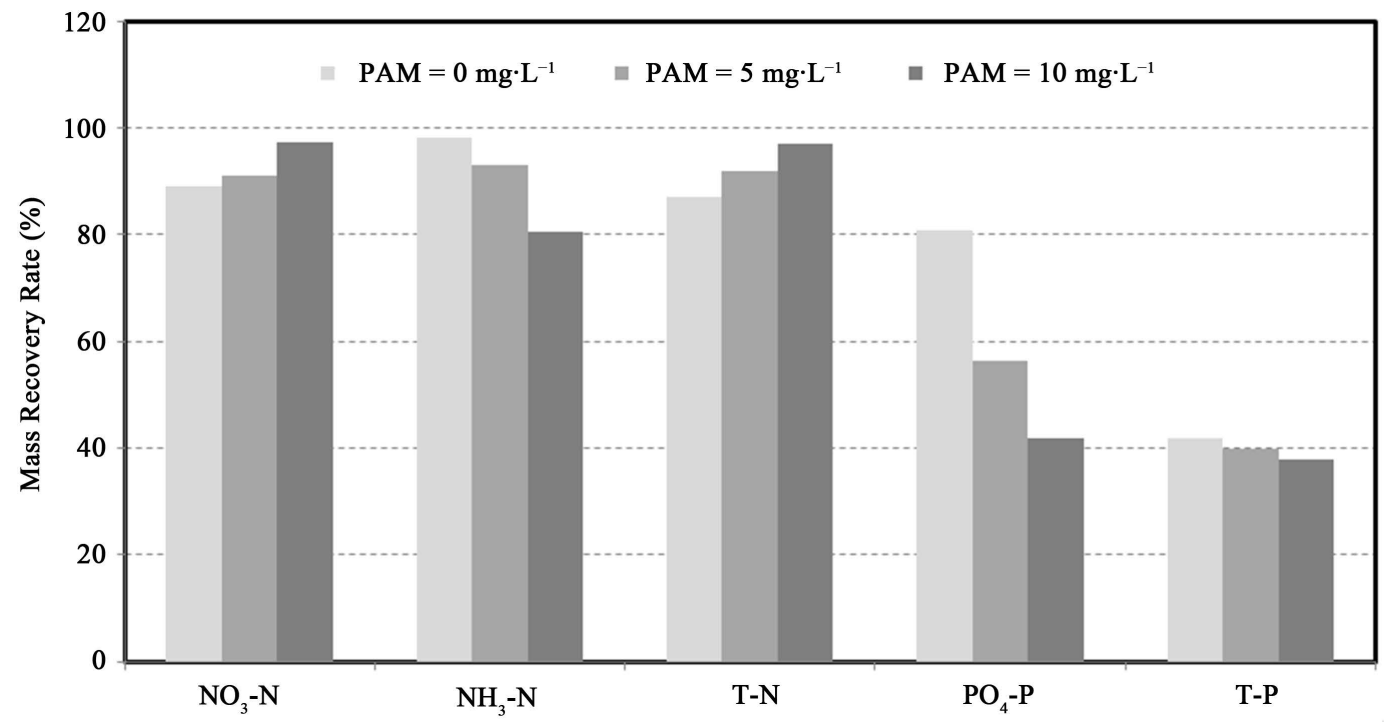

Figure 4. Mass recovery of major nutrients at different concentrations of PAM.

The findings of this study further indicated that PAM was capable of reducing the loss of major nutrients as water flowed through soil. Although our study results were encouraging, laboratory conditions limited by the vertical movement of nutrients along with soil-water did not represent field conditions. Therefore, further study was required to determine the optimal dose and application strategy for PAM under various field conditions.

\section{Acknowledgements}

This study was carried out with the support of the Research Program for Agricultural Science \& Technology Development (Project No. PJ0100832015), National Academy of Agricultural Science (NAAS), Rural Development Administration, Republic of Korea.

\section{References}

[1] Kim, M., Kim, S., Kim, J., Lee, S., Kim, Y. and Cho, Y. (2013) Biodegradable Check Dam and Synthetic Polymer, Its Experimental Evaluation for Turbidity Control of Agricultural Drainage Water. Korean Journal of Soil Science and Fertilizer, 46, 458-462. http://dx.doi.org/10.7745/KJSSF.2013.46.6.458 
[2] Smith, R.A., Schwarz, G.E. and Alexander, R.B. (1997) Regional Interpretation of Water Quality Monitoring Data. Water Resources Research, 33, 2781-2798. http://dx.doi.org/10.1029/97WR02171

[3] American Farmland Trust (2013) Annual Report. http://162.242.222.244/documents/AFT_ar2013_web.pdf

[4] Bahr, G.L. and Stieber, T.D. (1996) Reduction of Nutrient and Pesticides Losses through the Application of Polyacrylamide in Surface Irrigated Crops. Proceedings of Managing Irrigation-Induced Erosion and Infiltration with PAM, Twin Falls, 6-8 May 1996, 41-48.

[5] Entry, J.A. and Sojka, R.E. (2003) The Efficacy of Polyacrylamide to Reduce Nutrient Movement from an Irrigated Field. Transactions of the ASABE, 46, 75-83.

[6] Sojka, R.E., Lentz, R.D., Ross, C.W., Trout, T.J., Bjorneberg, D.L. and Aase, J.K. (1998) Polyacrylamide Effects on Infiltration in Irrigated Agriculture. Journal of Soil and Water Conservation, 53, 325-331.

[7] Lentz, R.D. (2003) Inhibiting Water Infiltration with Polyacrylamide and Surfactants: Applications for Irrigated Agriculture. Journal of Soil and Water Conservation, 58, 290-300.

[8] Lentz, R.D., Sojka, R.E. and Robbins, C.W. (1998) Reducing Phosphorus Losses from Surface-Irrigated Fields: Emerging Polyacrylamide Technology. Journal of Environmental Quality, 27, 305-312. http://dx.doi.org/10.2134/jeq1998.00472425002700020009x

[9] Lentz, R.D., Sojka, R.E. and Robbins, C.W. (1998) Reducing Soil and Nutrient Losses from Furrow Irrigated Fields with Polymer Applications. Advances in GeoEcology, 31, 1233-1238.

[10] Jung, Y., Yang, J., Park, C., Kwon, Y. and Joo, Y. (1998) Changes of Stream Water Quality and Loads of N and P from the Agricultural Watershed of the Yulmunchon Tributary of the Buk-Han River Basin. Korean Journal of Soil Science and Fertilizer, 41, 83-93.

[11] Heo, S., Jun, M., Park, S., Kim, K., Kang, S., Ok, Y. and Lim, K. (2008) Analysis of Soil Erosion Reduction Ratio with Changes in Soil Reconditioning Amount for Highland Agricultural Crops. Journal of Korean Society on Water Quality, 24, 185-194.

[12] Choi, B., Lim, J., Choi, Y., Lim, K., Choi, J., Joo, J., Yang, J. and Ok, Y. (2009) Applicability of PAM(Polyacrylamide) in Soil Erosion Prevention: Rainfall Simulation Experiments. Korean Journal of Environmental Agriculture, 28, 249257. http://dx.doi.org/10.5338/KJEA.2009.28.3.249

[13] Kim, M., Boone, S.A. and Gerba, C.P. (2009) Factors That Influence the Transport of Bacillus cereus Spores through Sand. Water, Air, and Soil Pollution, 199, 151-157. http://dx.doi.org/10.1007/s11270-008-9867-9

[14] Oosterbaan, R.J. and Nijland, H.J. (1994) Determining the Saturated Hydraulic Conductivity. Chapter 12, In: Ritzema, H.P., Ed., Drainage Principles and Applications, International Institute for Land Reclamation and Improvement (ILRI), Wageningen, 1125.

[15] American Public Health Association (APHA) (2012) Standard Methods for the Examination of Water and Wastewater. 22nd Edition, Washington DC, 4-156.

[16] Silva, L., Almeida, B., Melo, D., Marques, K. and Almeida, C. (2013) Polyacrylamide Effect on Hydraulic Conductivity of Hardsetting Soils in Northeast of Brazil. Geophysical Research Abstracts, 15, EGU2013-13309-2.

[17] Ketterings, Q., Reid, S. and Rao, R. (2007) Cation Exchange Capacity (CEC), Agronomy Fact Sheet Series (22). Cornel University Cooperative Extension.

[18] Lu, J.H., Wu, L. and Letey, J. (2002) Effects of Soil and Water Properties on Anionic Polyacrylamide Sorption. Soil Science Society of America Journal, 66, 578-584. http://dx.doi.org/10.2136/sssaj2002.5780 